Table 1 Abbreviations referring to use of library materials

\begin{tabular}{|llll|}
\hline Notes & $\begin{array}{l}\text { Using own notes e.g. lecture notes, notes } \\
\text { made previously from books etc. }\end{array}$ & Jnl & Journals \\
Lib Bks R & Library Books...on reading list/ recommended & Rew & Newspapers \\
Lib Bks W & Library Books...other wider reading & Reference e.g. dictionaries, directories \\
Own Bks R & Own Books...on reading list/ recommended & Inf & Information files \\
Own Bks W & Own Books...other wider reading & A-V & Audio-Visual e.g. videos, slides \\
F/T Bks R & $\begin{array}{l}\text { Friend's/Tutor's Books - on reading list/ } \\
\text { recommended } \\
\text { F/T Bks W }\end{array}$ & Friend's/Tutor's Books...other wider reading & AbsPrinted abstracts/indexes \\
\hline
\end{tabular}

Table 2 Abbreviations referring to use of library services

\begin{tabular}{|c|c|c|c|}
\hline $\mathrm{B} / \mathrm{R} / \mathrm{R}$ & Borrowing/returning/renewal & ILL & Inter-library loan service \\
\hline Pho & Photocopier & Res & Reservations \\
\hline WP & $\begin{array}{l}\text { Word-Processing facilities in the } \\
\text { library }\end{array}$ & Enq & $\begin{array}{l}\text { Enquiries relating to this } \\
\text { assignment }\end{array}$ \\
\hline Tables & $\begin{array}{l}\text { Study Tables - private study / } \\
\text { group work }\end{array}$ & SLC & Short Loan Collection \\
\hline Cat & Library catalogue & Lib & Library guides/publications \\
\hline
\end{tabular}

\title{
References
}

1 See Goodall, D. "Use of diaries in library and information research" Library and Information Research News Spring 1994, vol. 18, no.59, 17-21, for a detailed discussion of this methodology.

2 Hoy, C. and Hale, M. "A comparison of references cited by on-campus and off-campus graduate Library Sciences students"The Off-Campus Library Services Conference, Albuqueque, New Mexico, USA, October 30 - November 1, 1991 Proceedings Mt. Pleasant, Michigan, USA: Central Michigan University Press, 1991, 123-127.

3 The effectiveness of diaries as a method of determining how students spend their time. Leeds Metropolitan University, 1993 Internal document kindly made available by Mrs K. Crump

\section{Analysis of the impact of research information on practitioners}

\section{DOROTHY WILLIAMS, KAY WILSON and MICHAEL MCCONNELL}

School of Information and Media

The Robert Gordon University

\section{Introduction}

Research findings, if they are to fulfil their purpose, must be perceived as valuable and worth accessing. The role of research is to change the status quo, therefore findings need to be absorbed 
by practitioners. Research is more than a cycle of methodologies and data analysis techniques for other researchers to use and adapt. It is accepted that findings may not always be relevant to the problems or issues faced by practitioners. Practitioners need to be aware of the range of research undertaken and any findings, in order that they may make informed decisions. Much of the research that is undertaken within the information community addresses issues of concern to practitioners. However, the extent to which practitioners are aware of research, have access to research findings and particularly, how this impacts on their decision making is not well understood. To investigate the impact of research information on practitioners, it is necessary to look beyond outward behaviour patterns and to try to understand the internal processes which lead practitioners to decisions. There is a need to examine the knowledge of the practitioner and how it is applied. Such an approach would produce a fuller and more useful model of how and why research information impacts on practitioners.

Much research has been undertaken to investigate the decision making process and its attendant issues, but less research has been undertaken to study the impact on decision making of research findings. A number of studies have attempted to look at the perceptions of practitioners with regard to the importance of information on their decision making tasks. Koenig ${ }^{(1)}$, for example, provides a useful overview in this area.

Marshall ${ }^{(2)}$,outlined such an investigation into the impact of information services on decision making within the financial and health care sectors. She found that respondents generally agreed that the information from the information service led to better informed decisions. Forty four percent of respondents said that they had probably handled the situation differently as a result of the information received. It has to be noted that these studies were concerned with the impact of information services and not information itself, but they clearly illustrate one current approach to investigations of information and decision making. Although such studies gather interesting data, they are still one stage removed from really understanding the application of knowledge to decision making.

Another approach to investigating decision making is illustrated by Craghill and Wilson ${ }^{(3)}$. This study attempted to examine the impact of information research via these objectives:

"(1) to improve our understanding of the process by which research ideas are produced and ultimately taken up and used in practice.... (2) to substantiate the contention that education, through the library schools and in other ways, is a significant channel for the diffusion of research ideas, (3) to show that citation analyses alone are not an adequate way of measuring the impact of a given piece of research, (4) to provide indications as to how the impact of information can be assessed, (5) to provide indications to researchers as to how they can improve the likely impact of their research" (3, p.iv)

While certain useful information can be gathered from these studies, the need to get close to the knowledge base of the practitioner was not achieved.

There are obvious problems associated with research into the impact of information on decision making. Some methodologies are not close enough to the decision making itself, others can only deal with the perceptions of practitioners. The lack of in-depth research may be partly explained by the fact that the decision making process is very complex and influenced by many factors. 
This is highlighted in work by, for example, Williamson ${ }^{(4)}$ and Klein ${ }^{(5)}$. Klein underlines the following factors as influences on decision making:

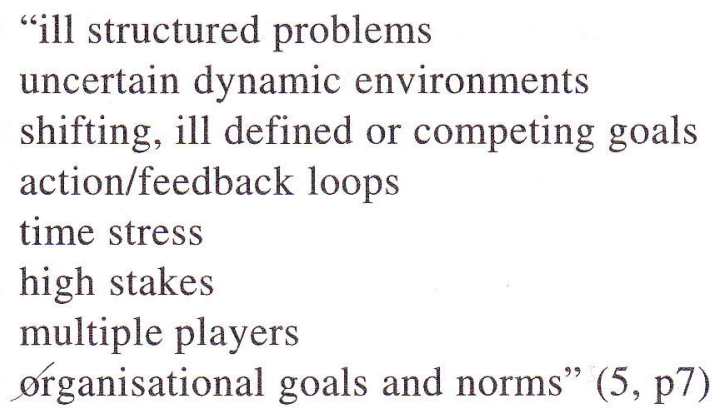

He also goes on to suggest that it is impossible to hold up one model as the only or best one to represent human decision making. He notes that decision making in the natural setting is not an individual, isolated task which can be separated from the rest of the working environment:

".... research shows that the decision event model does not characterise what fireground commanders report they actually do....The most fundamental difference is that in everyday situations, decisions are embedded in larger tasks that the decision maker is trying to accomplish. Decision event research in the lab tends to require decisions apart from any meaningful context. In natural settings, making a decision is not an end in itself" $(5, \mathrm{p} 6)$

In short, it is appreciated by the researchers that it is very difficult to get practitioners to isolate the impact of information in an abstract way. For example, a data collection tool such as the questionnaire which is impersonal, cannot, with regard to the complex environment within which decision making takes place, gather the depth of information required to enable a real understanding of the impact of information on practitioners.

The current study has adopted a new approach and methodology. This methodology will get nearer to the decision making by approaching the practitioners and decision makers in a natural setting with a semi-natural decision making task, or 'scenario', for them to complete. Such sessions will allow the researchers to discover exactly where, if at all, research findings impact upon the decision-making process.

This move towards linking with the practitioner in a natural setting via a semi-natural task is a step forward from the studies outlined above. Those studies either dealt with decision makers' retrospective perceptions of a decision making task or with the perceptions of the information providers and researchers. In either case the studies were several steps removed from the actual impact on decision making. This proposed study, while in effect still a pilot scheme, will move research a little closer to the issues critical to the effective and dynamic study of the impact, not only of research findings, but of information generally.

The field of information skills (IS) has been chosen as the area of investigation. Information skills research has been developing since the 1970 s and much research has been completed. Therefore there are enough substantial research findings available to make the study worthwhile and practical. IS has furthermore been chosen because it is a field in which the research team is relatively expert. There has been notable British Library research in this area and by concentrating on British Library funded research, largely in the schools sector, the proposed project would achieve the kind of focus necessary to pilot the research framework within a tight timescale. 
Moreover, as British Library IS research is a complex, but finite area, it will allow the researchers to investigate why practitioners use certain research findings and not others. This will enable the researchers to compare practitioners' level of knowledge with the channels of output they use. Finally, the information world is fairly comfortable with the term 'information skills'; the importance of the development of these skills in learners is not in dispute. Changes in educational philosophy have also meant that teaching staff should have more awareness of the need for pupils to develop information skills and strategies to aid them, as the curriculum moves steadily towards more pupil-centred learning and away from teacher-led teaching.

Craghill and Wilson ${ }^{(3)}$ also state that it is important to investigate an area which not only impacts on other researchers at the academic level but also impacts at the grass roots level. Information skills research has a strong link with both policy writing in school libraries and the curriculum as a whole.

Finally, this area is suitable for investigation as in Scotland professional librarians are in place in the majority of schools as decision makers. Such librarians thus have the potential to apply any research findings which may evolve.

\section{Method}

The study is taking place within five Phases. Phase 1 is the preparation stage where the method will be designed and developed. In Phase 2 the methodology will be tested on a group of respondents (teachers and representatives of Senior Management Teams with responsibility for resource management within schools). Initial findings will be gathered, analysed and presented in an interim report. Phase 3 will allow further investigation with the second group of respondents (librarians), and analysis. Phase 4 will include final data analysis, and involve interviews with researchers in other fields to obtain feedback and general evaluation on the method. Phase 5 will involve writing the final report, which will make recommendations on the transferability of the methodology.

\section{Phase 1}

The researchers are currently completing Phase 1 of the project, which involved the analysis of British Library IS research reports. Major and subsidiary findings were extracted from these reports, and developed into research maps. These maps were then used to develop the decision making scenarios and will also be used in Phases 2 and 3 as checklists of primary and secondary indicators to represent the breadth and depth of practitioners' research knowledge.

The researchers have discovered several major themes running through all of BL IS research; however, there are many sub-themes and report-specific findings perceived as valuable which may not be as obvious to practitioners. The themes have been codified into major, secondary and minor/ deep knowledge findings. Major and secondary findings have been presented in diagrammatic form, with codes. These codes are also presented separately on paper with sub-categories of minor/ deep knowledge findings grouped accordingly. During scenario sessions the diagram and codes will enable researchers to note the breadth and depth of research knowledge, and also allow them to pinpoint areas that the practitioner has not covered. Such areas can then be discussed in the follow-up interview. 
It was anticipated interviewees would spend up to an hour in interview sessions due to the highly discursive nature of discussion that would result from the scenarios. As interviews were being carried out during the working day, teachers, management and librarians might not be able to spend further time discussing demographic information. It was decided that a questionnaire was the most efficient way of gathering this information, and if time allowed, could double as an interview schedule. The questionnaire sought data on the interviewees' professional background and experience; the information sources on which they drew; their experience of professional organisations, their experience of INSET; courses and conferences; and their opinions of staff development and communication in the school.

On the basis of the research maps, the researchers developed decision making scenarios for teachers, senior management and school librarians. These scenarios present each category of practitioner with a problem, which the practitioners will then talk through with the researchers. The scenarios have been designed to be as natural as possible and incorporate (as much as possible) elements of major and secondary findings. The scenarios are about to be piloted on local schools, after which, revisions to the scenarios and interviews will be made where necessary.

\section{Phase 2}

On successful completion of the pilot, Phase 2 will implement the decision making scenarios in scenario sessions. During these sessions, teachers and SMT representatives will discuss and identify the knowledge they use to make decisions. The sessions will look at both the breadth and depth of practitioners' knowledge of research findings, as discussed above.

Scenarios will be followed by interviews and subsequent analysis. The interviews will be in two parts: the first part will, by means of the diagram and coded knowledge list, elicit further supplementary information about areas that had not been identified within the responses to the scenarios. The presence of the major indicators will indicate breadth of knowledge, and presence of the secondary and minor/deep indicators will indicate depth of knowledge. The second part of the interview will then identify the channels of output used by teachers and SMT representatives to detect research findings. The analysis will thus discover the extent of awareness about research findings and will also distinguish which channels of output decision makers use. The researchers will write an interim report at this stage. It will discuss the methodology and outline initial findings.

\section{Phase 3}

Phase 3 will run exactly as Phase 2, but the respondents will be librarians.

\section{Phase 4}

Data from teachers, SMT representatives and librarians will be analysed and the methodology evaluated. This will be achieved by reflection on the research and discussions with researchers working in other areas. As time is limited, it is intended that the feedback on the general applicability of the method to other areas would be sought via e-mail correspondence. Details of the project have already been posted to various information science and educational Listservs, and the response so far has been very encouraging. It would appear that researchers and practitioners from many disparate disciplines are interested in the transferability of the project's methodology. 


\section{Phase 5}

The final report for the project will be written and recommendations made for future use of the methodology.

\section{Conclusions arising from the pilot study}

The pilot study was smaller than was originally intended. This was due to the reorganisation of local government, forcing the pilot back some two months. Although reserve choices were available, it was impossible to obtain the acquiescence of a second primary in time for the pilot. This meant that the pilot ran into the beginning of the main study: there was no clean break. It was thus somewhat difficult to sit back and assess the mechanics of the study before instigating the main study. This meant that changes to the structure of interviews and the questionnaire were made progressively rather than all at once. Nevertheless the pilot was valuable for many reasons, which are discussed below.

1 The questionnaire:

The questionnaire was on the whole successful; only one revision was suggested. It transpired that none of the interviewees had time to complete the questionnaire at the time, so it was decided by the researchers that it was unrealistic to have the questionnaire doubling as an interview schedule, and that the questionnaire should be presented to interviewees at the end for completion in their own time. However, it became obvious that presenting the questionnaire to participants after the interview and then waiting for them to return it was problematic. Rates of return varied greatly and this affected the transcription and write up rate of the taped interviews. It was difficult to insert the salient information from the questionnaire and relate it after the scenario sessions were typed up. It was thus decided that for all future visits the questionnaire would be sent out with the introductory information in the hope that participants would complete the questionnaire prior to the researchers' visit.

2 The scenarios

The scenario sessions were, on the whole, considered a success; however, it was apparent that many of the participants saw them only as a starting point and did not strictly stick to them, preferrring to talk instead of their own practical experience. There were clear indications that interviewees who were less familiar with research were less familiar with research were less able to stick to the scenarios. Secondly, the fact that the scenarios attempted to be semi-natural was a problem. For example, participants in schools which already had an information skills policy in place had difficulty being questioned about how they would introduce an IS policy, as there was already one there. This meant that interviewees talked about their experience of existing IS policies rather than attempting to think about how such policies could best be introduced. The researchers were concerned that this might perhaps prevent interviewees drawing on their knowledge of research (either conscious or unconscious), because it was easier for them to draw on practical experience. As the set up of IS (or lack thereof) will differ from school to school it was difficult to see a way around this problem.

A second problem with the scenarios was that due to the inter-relatedness of each it was hard for participants to talk about any one in isolation. This was particularly true of more specific scenarios, for example, one which questioned interviewees about budget considerations. Some scenarios appeared to get interviewees talking more than others. 
Thirdly, it was clearly difficult for the reticent interviewees to talk at length without prompting. The researchers were wary of putting words in interviewees' mouths, but were forced in some cases to prompt for further information.

Fourthly, it was difficult to keep even the most garrulous and perceptive of the interviewees from departing from the subject of information skills, although this is an understandable result of the discursive interview format.

Overall, however, the scenario method of interview was considered a success: interviewees clearly had thought of the issues at hand in advance, and this enabled the researchers to maximise the (often limited) time available. Moreover, the discursive method of scenario interviewing allowed a great degree of information to be imparted in a limited period of time that a conventional interview schedule would almost certainly have missed. The original purpose of the study was being achieved by the scenarios; although perhaps not as precisely as was originally intended. Interviewees were revealing where information impacted; however, this was mainly because the interviewees were prompted to think in depth about their knowledge by talking through the scenarios, which they then discussed discursively, rather than by the scenarios per se. Thus although interviewees were not always discussing the scenarios as strictly as had been anticipated, they were nevertheless unconsciously revealing where information impacted on their decision making.

\section{General conclusions}

From the pilot, there are a considerable amount of variables relating to the impact of research and information dissemination. As each school has its own idiosyncratic organisation, it is extremely difficult to pinpoint where, if at all, research findings are impacting. Factors as varied as personality of individuals, size of school, catchment area, status of librarian, attitude of management, workload of teachers and many other factors all have an impact on whether research findings will have an effect. It is hard, but not impossible to distinguish when interviewees are drawing on their (conscious or unconscious) knowledge of research and when they are drawing on practical experience. At each of the pilot schools it appeared that there was an individual who would unofficially coordinate research findings and disseminate them to colleagues. Therefore although prima facie, it would seem difficult to draw conclusions, the researchers would contend that several main factors are most important and anticipate that the main study will validate these. These factors are as follows:

- Status of librarian

- Knowledge and education of librarian

- Attitude of management to library/librarian

- Attitude and knowledge of management regarding information skills

- Communication in school and lines of dissemination

- In the case of primaries, their links with the secondaries and other primaries.

Clearly the personality of the individual is of equal importance but this will be unique to each school, and moreover will be affected by the above points.

It is anticipated that the main study will validate the above contentions and moreover, it will be possible to tentatively draft "types" of school, and "types" of interviewee. In this way the research will be able to isolate the types of individuals and schools where research is having 
the greatest impact, and thus isolate exactly where research impacts on the decision making process.

\title{
Conclusions
}

It is anticipated that the results of this project will have the following benefits:

- Awareness will be raised about the true impact of research on decision making. This will be invaluable for all those involved in such research, funding bodies such as the British Library, and practitioners who stand to benefit from research findings.

- The methodology when proved successful, should be transferable to areas outwith the information skills area of library and information science. Moreover, the methodology will translate to decision making at different levels. This has encouraging implications for the value of future research.

\section{References}

1. Koenig, Michael. Libraries and their impact upon productivity. Paper presented at IFLA Presession seminar, Ankara, 14-18 August 1995.

2. Marshall, Joanne. The impact of information services on decision making: some lessons from the financial and health care sectors. Information Policy Briefings, No 1, March 1993.

3. Craghill, Denise and Wilson, TD. The impact of information research. British Library Research Paper 20. London: British Library, 1987.

4. Williamson, Peter. From dissemination to use: management and organisational barriers to the application of health services research findings, Health Bulletin, 50 (1), January 1992.

5. Klein, Gary A. et al (eds.). Decision making in action: models and methods. Norwood, New Jersey: Ablex, 1993.

\section{The Continuing Vocational Education training needs of records management practitioners}

\author{
LESLEY KING \\ Department of Information and Library Management. \\ University of Northumbria at Newcastle
}

\section{Background to the study}

Continuing professional development is a term regularly used and accepted in today's professional environment, and a concept recognised by the Higher Education Funding Council for England (HEFCE). In 1995 it established its CVE initiatives, and made funding available to organisations wishing to pursue related research and activities. 